\title{
A Hierarchical Linear Modeling Analysis of Working Memory and Implicit Prosody in the Resolution of Adjunct Attachment Ambiguity
}

\author{
Matthew J. Traxler
}

Published online: 18 April 2009

(C) The Author(s) 2009. This article is published with open access at Springerlink.com

\begin{abstract}
An eye-movement monitoring experiment investigated readers' response to temporarily ambiguous sentences. The sentences were ambiguous because a relative clause could attach to one of two preceding nouns. Semantic information disambiguated the sentences. Working memory considerations predict an overall preference for the second of the two nouns, as does the late closure principle (Frazier, On comprehending sentences: Syntactic parsing strategies. Ph.D. dissertation, University of Connecticut. West Bend, IN: Indiana University Linguistics Club, 1979). Previous studies assessing preferences for such items have obtained mixed results. On-line assessments show that working memory affects the degree of preference for the first noun, with lower capacity readers having a greater preference for the second noun (Felser et al., Language Acquisition: A Journal of Developmental Linguistics, 11, 127-163, 2003; Traxler, Memory \& Cognition, 35, 1107-1121, 2007). Offline assessments indicate the opposite pattern of preferences when the test sentences are displayed on a single line (Swets et al., Journal of Experimental Psychology: General, 136, 64-81, 2007). However, when implicit prosody is manipulated by displaying the sentences with a break between the second noun and the relative clause, the off-line assessments indicate that readers prefer to attach the relative clause to the first noun. In this experiment, readers' undertook a working memory assessment and then read test sentences that were displayed across two lines, with a break appearing after the second noun and before the relative clause. The eye-tracking data indicated an overall preference to attach the relative clause to the first noun, and there was little indication that working memory moderated the degree of preference for this configuration. Hence, it appears that readers' implicit prosodic contours rapidly affect resolution of adjunct attachment ambiguities.
\end{abstract}

Keywords Syntax - Grammar - Adjunct - Ambiguity resolution - Eye-tracking - Implicit prosody $\cdot$ Sentence processing $\cdot$ Working memory $\cdot$ Relative clause

M. J. Traxler $(\bowtie)$

Department of Psychology, University of California, Davis, 1 Shields Avenue, Davis, CA, 95616, USA

e-mail: mjtraxler@ucdavis.edu 


\section{Introduction}

A comprehensive theory of sentence processing should include a description of the processes used to structure sentences as well as the cognitive architecture in which those processes are carried out. A substantial amount of empirical work over the past two decades has been dedicated to investigating what role working memory resources play in syntactic parsing. On the shared resource account (Just and Carpenter 1992; Just et al. 1996; Just and Varma 2002), all cognitive processes, including syntactic parsing, draw upon a single working memory system. When the cognitive load associated with one process increases beyond some limit, other processes are delayed, cancelled, or subject to computational errors. The dedicated resource account (Caplan and Waters 1999; Waters and Caplan 1992) proposes instead that pre-interpretive language processes, including syntactic parsing, have exclusive access to a dedicated working memory system. On this kind of account, sentence-internal complexity can affect the speed and accuracy of parsing, but extrinsic load should not. Other theorists, especially those who adopt parallel-distributed processing models, view working memory capacity as epiphenomenal (e.g., MacDonald and Christiansen 2002). On this account, sentence parsing is a function of activation within neural networks. Because processing and representation are essentially inseparable, it makes no sense to talk about separate working memory resources.

The specific purpose of this project is to determine whether individual differences in working memory capacity influence readers' on-line parsing preferences. Such preferences are generally more compatible with the shared resource view than with the other two types of account sketched above (although discriminating between the shared and dedicated resource account requires a determination of when, exactly, working memory effects appear and what cognitive processes are affected; see, e.g., Caplan and Waters 1995; King and Just 1991; King and Kutas 1995; Traxler et al. 2002, 2005; Traxler and Tooley 2007; Waters and Caplan 1996a,b; Waters et al. 1995). The particular sentence type tested here includes a complex noun-phrase (NP) followed by a relative clause that can attach to either of the two nouns in the complex NP, as in 1a-c.

1a. The car of the driver that had the mustache was pretty cool.

1b. The driver of the car that had the mustache was pretty cool.

1c. The son of the driver that had the mustache was pretty cool.

Previous studies have shown that on-line and off-line attachment preferences for sentences like (1) depend on a variety of factors, including the type of preposition that appears within the complex NP, the type of modifying expression that follows, and language-general characteristics (Brysbaert and Mitchell 1996; Carreiras and Clifton 1993; Gilboy et al. 1995; Traxler et al. 1998; Zagar et al. 1997). This sentence type has been the focus of three recent studies looking at the relationship between working memory and parsing. They will be detailed in turn. ${ }^{1}$

${ }^{1}$ Cuetos and Mitchell's (1988) Cognition paper is indirectly related to the current experiment. This article reports two off-line experiments (one with Spanish and one with English participants) and three self-paced reading experiments, all of which were conducted with Spanish participants. The off-line judgment data for English show an approximate 60\% Noun 2 attachment preference. The off-line data were collected based on whole-sentence presentation. Although the self-paced reading portion of this study used similar items to the current experiment, and although the test sentences were displayed in three segments (not unlike the current presentation format), it is not directly relevant because (1) Cuetos and Mitchell manipulated ambiguity, but not attachment; (2) they did not conduct any on-line experiments with English speakers, (3) they found no ambiguity effects while participants were reading the relative clause, and (4) differences in reading time between ambiguous and unambiguous sentences all occurred in sentence-final regions, and so they could have been caused by differences in wrap-up effects across conditions rather than attachment processing. 
The first study looked at off-line and on-line parsing preferences in children whose working memory was assessed using the listening span test, an auditory variant of the Daneman and Carpenter (1980) sentence span test (Felser et al. 2003). In sentences like (1a-c), adults (whose working memory capacity was not tested) had faster overall processing time when the relative clause attached to the first noun in the NP-complex than when it attached to the second noun. Children's on-line attachment preferences varied with working memory capacity. Specifically, children with higher listening span scores showed the same preference as the adult participants. That is, they had shorter processing times when the relative clause attached to the first noun. Children with lower listening span scores preferred to attach the relative clause to the second of the two nouns. Felser and colleagues explained these findings by suggesting that high and low-capacity children made different use of the prosodic information available in the stimuli. Specifically, they suggested that high-capacity children grouped the entire NP-complex into a single prosodic phrase, which decreased the salience of the second noun. Under that scenario, forcing the relative clause to attach to the second noun would lead to processing difficulty (which they observed in the high-capacity children). Children with lower working memory capacity might prefer the second noun because it is closer to the relative clause, and so its trace would enjoy greater activation when the children reached the disambiguating region. Additionally, if they are less sensitive to prosodic cues, they might treat the sentence more as a list of words, which would further reduce the salience or accessibility of the initial noun.

The second recent study was a large-scale cross-linguistic project that investigated working memory effects on off-line preferences for sentences like (1c), which are globally ambiguous (Swets et al. 2007). The participants had their verbal and visual working memories assessed, and they completed a questionnaire that evaluated their attachment preferences for sentences like (1c). In the first experiment, the test sentences were displayed in their entirety for five seconds, and participants decided which noun the relative clause modified. Adult English speakers did not have a strong preference for either noun. Dutch speakers showed an overall preference to attach the relative clause to the first noun (which was the same preference as the adult English speakers in the Felser et al. 2003, study). Structural equation modeling was also used to explore whether working memory capacity affected participants' attachment preferences. English and Dutch speakers both showed increased preference for the first noun as their working memory capacities decreased, which is directly opposite of Felser and colleagues on-line results for children. Swets and colleagues, like Felser and colleagues, believed that prosodic factors may have affected attachment preferences, and that the working memory by attachment preference interactions could reflect differential sensitivity to this information, or differential grouping based on implicit prosody. Their prosodic hypothesis was somewhat different than Felser and colleagues', however. They suggested that low capacity comprehenders inserted a prosodic break between the noun phrase and the relative clause, but that high capacity comprehenders treated the entire noun phrase-relative clause complex as an integrated unit.

To test this latter hypothesis, Swets and colleagues conducted a second experiment in which they attempted to force a particular phrasal grouping. To do this, they displayed their test sentences in three segments. The first segment consisted of the noun-phrase complex (e.g., The daughter of the colonel), the second segment consisted of the relative clause (that had the limp), and the final segment consisted of the matrix verb-phrase (e.g., came home from school). Their reasoning was that this would force participants to insert a prosodic break between the second noun and the relative clause. This would cause them to treat the initial complex noun-phrase as an integrated unit. Under these conditions, all participants should prefer to attach the relative clause to the first noun, because it occupies a more salient position 
when the two nouns are treated as an integrated unit. Under the working memory hypothesis, low-capacity comprehenders should still prefer the local attachment site. The results indicated that preference for the first noun greatly increased in both English and Dutch speakers when the NP-complex was displayed on one line and the relative clause on another. In the English-speaking group, preference for the first noun was still predicted by working memory capacity, with the effect in the same direction as the first experiment (namely, preference for the first noun increased as working memory capacity decreased). For the Dutch speakers, displaying the NP-complex separate from the relative clause led to a strong preference for the first noun and eliminated any relationship between working memory capacity and attachment preferences (perhaps because there was little variability in attachment preferences for working memory to account for).

A third recent study Traxler (2007) was conducted to determine whether the opposing findings in the Felser et al. (2003) and Swets et al. (2007) studies were the result of differences in the participants' ages or differences in measurement procedures between the two studies. Recall that Felser and colleagues' (2003) study used an on-line preference assessment with children. Swets and colleagues' (2007) study used on off-line preference assessment with adults. Children showed an increase in Noun 1 preference with increased working memory capacity. Adults showed a decrease in Noun 1 preference with increased working memory capacity. This third study used an on-line assessment, eye-tracking (similar to Felser et al.'s on-line preference assessment) and adult participants (similar to Swets et al.'s population). Participants were tested using a variant of the sentence span test (Turner and Engle 1989). They then had their eye-movements monitored while they read sentences like $(1 \mathrm{a}-\mathrm{c})$. The eye movement data showed that disambiguating noun phrases in sentences like (1c) had shorter total times than the ambiguous counterparts (1b), and (1c). Working memory did not moderate the text variable effects in any of the early processing measures (first pass or first-pass regressions) prior to the post-disambiguating region. In the post-disambiguating region, there were working memory by sentence type interactions that showed that readers with higher working memory capacity preferred to attach the relative clause to the first noun and had elevated total time relative to lower capacity comprehenders when the relative clause modified the second noun. These results are consistent with Felser and colleagues' on-line results with children, which again run counter to Swets and colleagues' offline results with adults. One conclusion from these studies is that the difference between the off-line and online preferences reflect differences in tasks, rather than developmental differences in parsing processes.

The question remains, however, whether the individual differences in the strength of attachment preferences are the result of working memory restrictions or some other factor that coincides with working memory. Swets and colleagues (2007) appealed to implicit prosody to explain their findings and showed that off-line preferences change dramatically when visual segmentation was used to influence the way participants grouped words into (implicit) prosodic phrases. The main goal of the current experiment was to determine whether this implicit prosodic phrasing translated into differences in on-line attachment preferences. To do so, the test sentences were displayed with the NP-complex on the first line, and the relative clause was displayed starting at the left edge of the second line; this was the same display technique used by Swets and colleagues in their Experiment 2. Setting up the display in this manner should have two chief effects. First, it should strengthen participants' preferences for the first noun as the host of the relative clause modifier and decrease the preference for the second noun. This manipulation should therefore either lead to decreased processing time when the relative clause attaches to the first noun and/or increased processing time when the relative clause attaches to the second noun (or both). The other chief effect 
should be a reduction or elimination of any moderation of attachment preferences by working memory capacity. Recall that in the Swets et al. study, working memory effects on attachment preferences were greatly reduced when the test sentences were displayed on two lines (and eliminated altogether in the Dutch speakers). By contrast, if working memory restrictions are the sole factor affecting on-line attachment preferences for sentences like (1a-c), then low-capacity readers should prefer the second noun over the first noun, with high-capacity readers showing the opposite preference (as in Felser et al. 2003; Traxler 2007).

\section{Method}

Participants

Fifty-four undergraduates from the University of California, Davis participated in return for course credit. All of the participants were native speakers of English and had normal uncorrected vision and hearing.

Stimuli

The test sentences consisted of 24 sets of sentences like ( $1 \mathrm{a}-\mathrm{d})$. The sentences were modified versions of the test sentences from Traxler et al. (1998). The sentences were changed to replace British English terms with American English terms. All of the items appear in the Appendix. In addition, an unambiguous baseline condition, as in (1d), was added.

(1a) The writer of the letter// that had/ blonde hair/ arrived this/ morning. (Noun 1)

(1b) The letter of the writer// that had/ blonde hair/ arrived this/ morning. (Noun 2)

(1c) The sister of the writer// that had/ blonde hair/ arrived this/ morning. (either)

(1d) The sister/ that had/ blonde hair/ arrived this/ morning. (unambiguous)

"/" marks indicate where the sentences were segmented for analysis. "//" indicates where the line break occurred in the ambiguous conditions. Animacy and plausibility were controlled, as was frequency of the nouns in the initial NP complex (by counterbalancing across items; Traxler et al. 1998; Traxler 2007).

These items were originally designed as part of a larger study that investigated how different types of noun-phrases and different kinds of modifying expressions affect readers' on-line parsing decisions (Traxler et al. 1998). All of the noun-phrases had the preposition "of" between the two nouns. This kind of preposition is said to be non-theta-assigning, because it does not directly assign a semantic role to the following noun (see Frazier and Clifton 1996; Gilboy et al. 1995; for the linguistic rationale behind this claim). According to the Construal hypothesis, both the first noun and the second noun will be available to host a relative clause modifier when the two nouns in the subject noun-phrase are connected by a non-theta-assigning preposition. Within that framework, however, the items that were included in the experiment express a number of different kinds of relationships. About half of the items had relational nouns, like uncle, sister, niece, which entail two connected entities (one cannot be an uncle unless there is also a niece or nephew). Some of the other items expressed other semantic relationships, such as possession (as in car of the driver) or authorship (writer of the song). Attachment preferences could vary according to the details of the relationship between the two nouns. For example, one might find greater recency preferences for kinship relations than for owner-possession relations. In fact, Gilboy et al.'s (1995) 
study provided some evidence that Spanish speakers' preferences vary according to detailed aspects of sentences like 1a-d. However, a number of current parsing accounts, such as Gibson's (2000), SPLT/DLT account, Frazier and Clifton's (1996), Construal hypothesis, and Frazier (1979), garden path theory, do not predict systematic differences in the strength of preference in on-line attachment within the kinds of items that were used in the experiment.

The scoring regions were identical across conditions. In the (a) and (b) versions, one of the attachments was much more plausible than the other (as established previously by plausibility pre-testing). So, in (1a), the relative clause that had blonde hair must ultimately be assigned to modify the writer rather than the letter because the former leads to a highly plausible interpretation (with a mean rating of 6.0 across all the items on a scale of $0-7$, with 7 being the most plausible) while the latter leads to a highly implausible interpretation (with a mean rating of 1.0 across items on the same scale).

The test sentences were presented along with 87 other sentences. 48 sentences were from an additional experiment involving modifier-goal ambiguities and the remainder were filler sentences of various grammatical types. Items were assigned to lists in a pseudo-randomized order, such that equal numbers of each sentence type appeared on each list and so that each participant saw only one version of each item. At least one sentence intervened between each test sentence from this experiment.

With the exception of the unambiguous condition, which was always displayed on a single line, the test sentences were displayed across two lines, with the line break occurring immediately following the second noun in the NP-complex. This manipulation is based on the display characteristics in Swets et al. (2007) Experiment 2. They showed that off-line preferences change dramatically under these conditions, with participants heavily favoring attachment to the first noun. The purpose of this experiment was to determine whether this off-line preference corresponds to an on-line attachment preference.

\section{Working Memory Testing}

Working memory was assessed using the method advocated by Waters and Caplan (2003), based on their psychometric evaluation of a wide variety of working memory tasks. The three tasks used were sentence span, alphabet span, and minus span.

Participants first completed a variant of the Daneman and Carpenter (1980) sentence-span test (Turner and Engle 1989). Participants were presented with groups of sentences to read aloud. Each sentence was followed by an unrelated target word that the participants were to remember. After reading all of the sentences in a group, participants were asked to recall all of the target words in order. The number of sentences and the number of target words in a group increased from two to six as participants proceeded through the task. Participants saw three groups of the same size before they saw the next larger group. They were initially given three groups of two sentences as practice. Participants were assigned a raw score based on the total number of words recalled in the correct serial position (see Waters and Caplan 2003).

Next, participants completed the alphabet span test. In this test, participants read sets of single-syllable words aloud. Set sizes ranged from two to six words. After reading a set of words aloud, participants mentally rearranged them into alphabetical order and wrote them down on an answer sheet. There were five trials at each set size. Participants' scores were based on the total number of words recalled in the correct serial position.

Finally, participants completed the minus span test. In this task, participants read sets of random digits out loud, subtracted 2 from each digit, and reported the result in the proper 
order. Set sizes ranged from 2 to 8 digits. Participants completed five trials at each set size. Participants' scores were based on the total number of digits reported in the correct serial position.

Participants' mean scores across the three tests was used as the estimate of working memory capacity in the models reported below. This composite measure was used because it produced the best test-retest reliability in a psychometric evaluation of a number of working memory assessment methods (Waters and Caplan 2003). Variability in administration procedures, scoring methods, and sensitivity to nuisance variables like participants' motivation and level of alertness limit the replicability of effects obtained in working memory studies. In particular, the reliability of working memory tests like the sentence span test has been a long-standing concern in individual differences research. There are also issues relating to whether working memory is a unitary construct, or whether, like intelligence, it is possible to fractionate working memory into separate capacities (Swets et al. 2007, provide a general overview of these issues). Because the reliability of the individual difference assessment places an upper bound on the validity of any results obtained when that assessment technique is used, it is important to use an individual difference measure with the highest possible reliability.

\section{Eye-movement Monitoring Procedure}

A Fourward Technologies dual-Purkinje image eye-tracker monitored participants' eye movements while they read the test sentences. The tracker has angular resolution of $10^{\prime}$ of arc. The tracker monitored only the right eye's gaze location. A PC displayed materials on a VDU seventy cm from participants' eyes. The location of participants' gaze location was sampled every millisecond and the PC software recorded the tracker's output to establish the sequence of eye fixations and their start and finish times. Before the experiment, the experimenter seated the participant at the eye tracker and used a bite plate and head rests to minimize head movements. After the tracker was aligned and calibrated, the experiment began. After reading each sentence, the participant pressed a key. After some of the filler sentences, the participant responded to a comprehension question. Participants did not receive feedback on their responses. All of the participants in the analyses reported below scored at $90 \%$ accuracy or above on the comprehension questions. Between each trial, a pattern of squares appeared on the computer screen along with a cursor that indicated the participants' current gaze location. If the tracker was out of alignment, the experimenter recalibrated it before proceeding with the next trial.

\section{Analyses}

Four standard eye-movement measures were computed for each participant. First-pass time is the sum of all fixation durations beginning with the first fixation in a region until the reader's gaze leaves the region, left or right. First-pass regressions is the number of eye-movements that crossed a region's left-hand boundary immediately following a first-pass fixation. Regression-path time includes all fixation durations from the first fixation in a region until the reader's gaze crosses the right-hand boundary of the region. This measure includes re-fixations of preceding regions and the target region itself. Total time is the sum of all fixation durations in a region, regardless of order. Three scoring regions were analyzed ("/" marks in the Appendix indicate region boundaries). The pre-noun region consists of the beginning of the relative clause up to the head noun (e.g., the words that had). The noun 
region consisted of the noun within the relative clause and the preceding adjective for items that had one. The post-noun region consisted of the two words immediately following the noun region. Sometimes effects linger past the region where the critical information lies, and semantic (plausibility) differences can be somewhat slow to appear in the eye-movement record (relative to grammatical violations or semantic anomalies caused by animacy violations; Rayner et al. 2004; Traxler et al. 2002).

Prior to determining fixation durations, an automatic procedure incorporated fixations of less than $80 \mathrm{~ms}$ into the largest fixation within one character. In the next stage, the procedure eliminated all individual fixations greater than $1,000 \mathrm{~ms}$ and less than $80 \mathrm{~ms}$. Subsequently, first pass times, regression-path, and total times of less than $120 \mathrm{~ms}$ were excluded from the analyses. Finally, any first-pass, regression-path, or total times exceeding 3,000 ms were excluded. These procedures together led to $3.6 \%$ of the data being excluded.

Prior to analyzing the data, we computed coefficient alpha for the four dependent measures based on data from the noun region. Coefficient alpha for first-pass, first-pass regressions, regression path time, and total time was $0.84,0.67,0.88$, and 0.86 , respectively.

The purpose of the hierarchical linear modeling was to determine what preference readers had (if any) in determining where to attach the relative clause and whether these preferences were affected by working memory capacity. Each participant had up to 24 responses. Missing responses were due to track loss, extremely short, or extremely long fixations (as described above). Dependent measure outcomes were considered a function of attachment (relative clause attaches to the first noun vs. second noun vs. either noun vs. unambiguous condition). This constituted the first level of the model in which the effects of item properties on outcomes could vary across subjects. The second level tested main and moderating effects of working memory capacity (WMC) on the associations between item properties and the response, where the moderating effects were tested by including interactions between item properties and WMC. WMC was estimated for each subject by taking the arithmetic mean of the raw number of correct responses on the sentence-span test (with 60 as the maximum possible score, and 0 as the lowest possible), alphabet span test (with 100 as the maximum, 0 as the minimum), and minus span (with 175 as the maximum, 0 as the minimum possible). WMC was centered at the sample mean of $86.2(\min =58.3$, $\max =108)$. Finally, it is important to note that estimation of the level-1 and level-2 associations occurred simultaneously (Raudenbush and Bryk 2002; Snijders and Bosker 1999; see also Blozis and Traxler 2007; Traxler 2007).

Separate models were fitted for each dependent measure for each scoring region. The models tested for an effect of sentence type (relative clause attaches to the first noun vs. the second noun vs. either noun vs. unambiguous condition). The models also tested whether the text variable effects differed across participants with different working memory scores. The model parameters are listed in Table 1.

\section{Results}

Table 2 presents mean values for the four dependent measures by region and condition. Table 3 presents the results of the hierarchical linear models.

Consider first effects that occurred in the pre-noun region. First pass, regression path, and total time data all produced shorter fixation times in the unambiguous than the ambiguous conditions. This likely reflects the fact that the pre-noun region in the ambiguous conditions appeared at the beginning of the second line while the corresponding region in the unambiguous condition was contiguous with the following region. Thus, elevated times relative 
Table 1 Model parameters

Model

Level 1: $\quad$ RT for person $\mathrm{i}$, for sentence $\mathrm{j}=\beta_{0 \mathrm{i}}+\beta_{1 \mathrm{i}}($ Noun 1 condition $)+\beta_{2 \mathrm{i}}($ Noun 2 condition $) \mathrm{j}$

$\quad+\beta_{3 \mathrm{i}}(\text { eithercondition })_{\mathrm{j}} \varepsilon_{\mathrm{ij}}$
Level 2: $\quad \beta_{0 \mathrm{i}}=\gamma_{00}+\gamma_{01}(\text { composite working memory })_{\mathrm{i}}+\mathrm{u}_{0 \mathrm{i}}$

$\beta_{1 \mathrm{i}}=\gamma_{10}+\gamma_{11}$ (composite working memory $)_{\mathrm{i}}+\mathrm{u}_{1 \mathrm{i}}$

$\beta_{2 \mathrm{i}}=\gamma_{20}+\gamma_{21}(\text { composite working memory })_{\mathrm{i}}+\mathrm{u}_{2 \mathrm{i}}$

$\beta_{2 \mathrm{i}}=\gamma_{30}+\gamma_{31}(\text { composite working memory })_{\mathrm{i}}+\mathrm{u}_{3 \mathrm{i}}$

$\gamma_{00}$ is the grand mean reading time for the baseline condition, when working memory is set to the sample mean

$\gamma_{01}$ is the average change in reading time per unit change in working memory for the baseline condition

$\gamma_{10}$ is the average outcome for the Noun 1 condition when working memory is set to the sample mean

$\gamma_{11}$ is the average change in the Noun 1 attachment effect per unit change in working memory

$\gamma_{20}$ is the average outcome for the Noun 2 condition when working memory is set to the sample mean

$\gamma_{21}$ is the average change in the Noun 2 attachment effect per unit change in working memory

$\gamma_{30}$ is the average outcome for the either condition when working memory is set to the sample mean

$\gamma_{31}$ is the average change in the either attachment effect per unit change in working memory

$\mathrm{u}_{0 i}, \mathrm{u}_{1 \mathrm{i}}$, and $\mathrm{u}_{2 \mathrm{i}}, \mathrm{u}_{3 \mathrm{i}}$ are the errors for the level-2 intercept and slope equations

Table 2 Mean first pass, first-pass regressions, regression path time, and total time by region and condition

\begin{tabular}{llll}
\hline Condition & \multicolumn{2}{l}{ Region } & \\
\cline { 2 - 3 } & Pre-noun & Noun & Post-noun \\
\hline First pass time & & & \\
Unambiguous & 417 & 640 & 531 \\
Noun 1 & 542 & 654 & 508 \\
Noun 2 & 545 & 643 & 502 \\
Either & 540 & 630 & 520 \\
First pass regressions & & & \\
Unambiguous & $10.7 \%$ & $13.8 \%$ & $27.0 \%$ \\
Noun 1 & $1.26 \%$ & $17.6 \%$ & $33.0 \%$ \\
Noun 2 & $4.40 \%$ & $18.6 \%$ & $35.2 \%$ \\
Either & $3.14 \%$ & $15.4 \%$ & $29.9 \%$ \\
Regression path time & & & \\
Unambiguous & 489 & 772 & 780 \\
Noun 1 & 551 & 830 & 842 \\
Noun 2 & 585 & 865 & 925 \\
Either & 572 & 805 & 854 \\
Total time & & & \\
Unambiguous & 557 & 843 & 642 \\
Noun 1 & 694 & 903 & 617 \\
Noun 2 & 722 & 964 & 651 \\
Either & 682 & 890 & 652 \\
\hline
\end{tabular}

to the unambiguous condition are likely due to orienting effects following a return sweep in the ambiguous conditions, rather than an effect of differential processing load. This conclusion is further supported by the first-pass regressions effects, which were in the opposite 
Table 3 Results of the hierarchical linear models

\begin{tabular}{|c|c|c|c|c|}
\hline & $\begin{array}{l}\text { First pass } \\
\text { time }\end{array}$ & $\begin{array}{l}\text { First pass } \\
\text { regressions }\end{array}$ & $\begin{array}{l}\text { Regression } \\
\text { path time }\end{array}$ & $\begin{array}{l}\text { Total } \\
\text { time }\end{array}$ \\
\hline \multicolumn{5}{|l|}{ Pre-noun region } \\
\hline Baseline (unambiguous condition) & $\begin{array}{l}416 \\
(16.1)\end{array}$ & $\begin{array}{l}10.7 \\
(1.81)\end{array}$ & $\begin{array}{l}489 \\
(21.8)\end{array}$ & $\begin{array}{l}557 \\
(25.5)\end{array}$ \\
\hline WMC effect on baseline RT & $\begin{array}{l}-5.50 * * \\
(1.91)\end{array}$ & $\begin{array}{l}-0.24 \\
(0.21)\end{array}$ & $\begin{array}{l}-7.71 * \\
(3.11)\end{array}$ & $\begin{array}{l}-6.49 * \\
(3.00)\end{array}$ \\
\hline Noun 1 attachment effect & $\begin{array}{l}125 * * \\
(29.2)\end{array}$ & $\begin{array}{l}-9.43 * * \\
(1.73)\end{array}$ & $\begin{array}{l}62.0 * * * \\
(32.9)\end{array}$ & $\begin{array}{l}136^{* *} \\
(31.5)\end{array}$ \\
\hline WMC effect on Noun 1 attachment effect & $\begin{array}{l}-0.27 \\
(1.72)\end{array}$ & $\begin{array}{l}0.20 \\
(0.16)\end{array}$ & $\begin{array}{l}2.18 \\
(2.32)\end{array}$ & $\begin{array}{l}-2.13 \\
(2.10)\end{array}$ \\
\hline Noun 2 attachment effect & $\begin{array}{l}128 * * \\
(29.4)\end{array}$ & $\begin{array}{l}-6.29 * * \\
(2.31)\end{array}$ & $\begin{array}{l}95.5 * * \\
(30.3)\end{array}$ & $\begin{array}{l}165^{* *} \\
(33.5)\end{array}$ \\
\hline WMC effect on Noun 2 attachment effect & $\begin{array}{l}0.17 \\
(2.55)\end{array}$ & $\begin{array}{l}0.15 \\
(0.26)\end{array}$ & $\begin{array}{l}1.76 \\
(3.30)\end{array}$ & $\begin{array}{l}0.93 \\
(3.01)\end{array}$ \\
\hline Either attachment effect & $\begin{array}{l}123 * * \\
(25.1)\end{array}$ & $\begin{array}{l}-7.55^{* *} \\
(2.28)\end{array}$ & $\begin{array}{l}83.4 * * \\
(26.0)\end{array}$ & $\begin{array}{l}125 * * \\
(24.7)\end{array}$ \\
\hline WMC effect on Either attachment effect & $\begin{array}{l}0.27 \\
(1.70)\end{array}$ & $\begin{array}{l}0.17 \\
(0.25)\end{array}$ & $\begin{array}{l}1.92 \\
(1.99)\end{array}$ & $\begin{array}{l}-0.71 \\
(1.63)\end{array}$ \\
\hline \multicolumn{5}{|l|}{ Noun region } \\
\hline Baseline (unambiguous condition) & $\begin{array}{l}640 \\
(23.6)\end{array}$ & $\begin{array}{l}13.8 \\
(2.25)\end{array}$ & $\begin{array}{l}772 \\
(32.9)\end{array}$ & $\begin{array}{l}843 \\
(30.6)\end{array}$ \\
\hline WMC effect on baseline RT & $\begin{array}{l}-4.21^{* * *} \\
(2.44)\end{array}$ & $\begin{array}{l}0.33 \\
(0.25)\end{array}$ & $\begin{array}{l}-5.29 \\
(3.25)\end{array}$ & $\begin{array}{l}-5.51 * * * \\
(3.13)\end{array}$ \\
\hline Noun 1 attachment effect & $\begin{array}{l}13.6 \\
(23.5)\end{array}$ & $\begin{array}{l}3.77 \\
(2.86)\end{array}$ & $\begin{array}{l}57.8 \\
(35.4)\end{array}$ & $\begin{array}{l}59.6 \\
(36.4)\end{array}$ \\
\hline WMC effect on Noun 1 attachment effect & $\begin{array}{l}-0.11 \\
(2.43)\end{array}$ & $\begin{array}{l}-0.55^{*} \\
(0.24)\end{array}$ & $\begin{array}{l}-4.54 \\
(3.04)\end{array}$ & $\begin{array}{l}-3.69 \\
(3.54)\end{array}$ \\
\hline Noun 2 attachment effect & $\begin{array}{l}3.42 \\
(23.9)\end{array}$ & $\begin{array}{l}4.72 \\
(2.94)\end{array}$ & $\begin{array}{l}93.3 * \\
(38.5)\end{array}$ & $\begin{array}{l}120 * * \\
(39.7)\end{array}$ \\
\hline WMC effect on Noun 2 attachment effect & $\begin{array}{l}-1.84 \\
(2.42)\end{array}$ & $\begin{array}{l}-0.24 \\
(0.27)\end{array}$ & $\begin{array}{l}-2.72 \\
(2.78)\end{array}$ & $\begin{array}{l}-2.61 \\
(4.05)\end{array}$ \\
\hline Either attachment effect & $\begin{array}{l}-9.48 \\
(25.6)\end{array}$ & $\begin{array}{l}1.57 \\
(2.89)\end{array}$ & $\begin{array}{l}33.0 \\
(39.2)\end{array}$ & $\begin{array}{l}46.8 \\
(38.5)\end{array}$ \\
\hline WMC effect on Either attachment effect & $\begin{array}{l}0.26 \\
(3.27)\end{array}$ & $\begin{array}{l}-0.60 * * * \\
(0.31)\end{array}$ & $\begin{array}{l}-3.26 \\
(3.36)\end{array}$ & $\begin{array}{l}0.86 \\
(3.90)\end{array}$ \\
\hline \multicolumn{5}{|l|}{ Post-noun region } \\
\hline Baseline (unambiguous condition) & $\begin{array}{l}531 \\
(17.2)\end{array}$ & $\begin{array}{l}27.0 \\
(3.06)\end{array}$ & $\begin{array}{l}779 \\
(38.7)\end{array}$ & $\begin{array}{l}642 \\
(21.5)\end{array}$ \\
\hline WMC effect on baseline RT & $\begin{array}{l}0.12 \\
(1.64)\end{array}$ & $\begin{array}{l}-0.28 \\
(0.27)\end{array}$ & $\begin{array}{l}-2.26 \\
(3.35)\end{array}$ & $\begin{array}{l}-0.84 \\
(2.08)\end{array}$ \\
\hline Noun 1 attachment effect & $\begin{array}{l}-23.4 \\
(20.8)\end{array}$ & $\begin{array}{l}5.97 \\
(3.77)\end{array}$ & $\begin{array}{l}62.5 \\
(55.1)\end{array}$ & $\begin{array}{l}-25.3 \\
(28.6)\end{array}$ \\
\hline
\end{tabular}


Table 3 continued

\begin{tabular}{lllll}
\hline & $\begin{array}{l}\text { First pass } \\
\text { time }\end{array}$ & $\begin{array}{l}\text { First pass } \\
\text { regressions }\end{array}$ & $\begin{array}{l}\text { Regression } \\
\text { path time }\end{array}$ & $\begin{array}{l}\text { Total } \\
\text { time }\end{array}$ \\
\hline Noun 2 attachment effect & -29.6 & $8.18^{* *}$ & $145^{* *}$ & 9.45 \\
WMC effect on Noun 2 attachment effect & $(19.2)$ & $(3.07)$ & $(56.6)$ & $(25.4)$ \\
& -1.95 & -0.06 & -0.80 & 0.54 \\
Either attachment effect & $(1.94)$ & $(0.25)$ & $(4.86)$ & $(1.81)$ \\
& -11.0 & 2.83 & 74.3 & 10.4 \\
WMC effect on Either attachment effect & $(15.8)$ & $(3.47)$ & $(61.2)$ & $(23.9)$ \\
& -1.97 & 0.30 & 4.45 & 1.23 \\
& $(1.49)$ & $(0.29)$ & $(5.66)$ & $(1.56)$ \\
\hline
\end{tabular}

Notes: $*$ Indicates effect different from baseline at $p<0.05$. ** Indicates effect different from baseline at $p<0.01$. $* * *$ Indicates effect different from baseline at $0.05<p<0.10$. All $t$-tests are two-tailed. WMC was centered at the sample mean, 86.2. Estimates are full maximum likelihood. Standard errors are in parentheses. Outcomes are reported in milliseconds (except for \% first pass regressions)

direction. Here, the unambiguous condition had substantially more first-pass regressions than the ambiguous conditions. Working memory affected baseline reading time, which decreased with increases in working memory scores in first pass, regression path, and total time. There were no other interactions between working memory capacity and sentence type.

Data from the noun region showed that readers preferred to attach the relative clause to the first noun rather than the second. Regression path and total time were both elevated relative to the baseline unambiguous condition when the relative clause attached to the second noun (by $93.3 \mathrm{~ms}$ in regression path time and $120 \mathrm{~ms}$ in total time; see Table 3 ).

In addition to the models reported in Table 3, two additional models were computed for the total time data from the noun region. These models directly test for differences between the Noun 1 condition and the Noun 2 condition, and the Noun 1 and either condition. The first of these models tested for a difference between the Noun 1 and Noun 2 conditions. This model showed a significant $60 \mathrm{~ms}$ total time advantage for the Noun 1 attached modifiers $[t(51)=2.12, p<0.05]$. This difference did not interact with working memory capacity $[t(51)<1, \mathrm{NS}]$. The second model tested for a difference between the Noun 1 and either condition. This model showed a significant $72 \mathrm{~ms}$ advantage for the either condition $[t(51)=2.18, p<0.05]$, which also did not interact with working memory capacity $[t(51)=1.07, \mathrm{NS}]$.

As in the previous region, the full models provided some indication that higher capacity readers read the sentences faster than lower capacity comprehenders. This is suggested by two trends towards a cross-level interaction between working memory capacity and the intercept (baseline RT), which occurred in the first pass and total time data. Also as in the previous region, there was little indication that working memory capacity moderated attachment preferences. One exception, however, was the effect of working memory capacity on the difference between the unambiguous baseline condition and the Noun 1 condition in first-pass regressions (see Table 3 ). There was a decrease of $0.55 \%$ in first-pass regressions with each unit increase in working memory capacity. This might indicate that higher capacity comprehenders had greater preference for the first noun than lower capacity comprehenders, which would be compatible with Felser and colleague's (2003) results as well as the pattern observed in Traxler (2007). This result should be viewed with some caution, however, as it occurs only in first-pass regressions, which is a less reliable measure than the other three 
(as indicated by coefficient alpha values for the four dependent measures). There were no other indications that differences between conditions were moderated by working memory capacity in the noun region.

The post-noun region also produced evidence that readers preferred to attach the relative clause to the first noun rather than the second. The Noun 2 condition had elevated first-pass regressions and regression-path time when compared to the baseline unambiguous condition. No other condition effects were significant in the post-noun region, and there was no indication in any of the dependent measures that working memory affected readers' response to the different types of sentences.

One final negative result deserves some comment. Namely, although reading times relative to the unambiguous baseline were elevated when the relative clause attached to the second noun, the Noun 1 and either conditions were just as easy to process as the unambiguous condition. This replicates previous results for this sentence type (Traxler et al. 1998; Traxler 2007), and further demonstrates that syntactic ambiguity, by itself, is not costly.

\section{General Discussion}

The purpose of this study was to determine whether segmenting sentences containing a complex noun phrase followed by a relative clause would affect readers' on-line attachment preferences. An additional goal was to determine whether attachment preferences would be affected by individual differences in working memory capacity under these display conditions. Regression-path and total time data from the noun region indicated that readers had greater difficulty integrating the relative clause when semantic information indicated that the relative clause should attach to the second noun, relative to an unambiguous baseline condition. First-pass regressions and regression-path data from the post-noun region also indicated that the relative clause was more difficult to process when it attached to the second noun relative to unambiguous control sentences. Analyses of the total time data from the noun region indicated that the Noun 2 condition was more difficult to process than either the Noun 1 condition or the either condition.

Other than varying with overall processing speed, there was little indication that working memory capacity moderated any of the text characteristic effects. In general, when working memory effects were observed, the data indicated that participants with higher working memory test scores had shorter overall processing times. Further, these effects were largely limited to the pre-noun region, where they were significant in all of the dependent measures except first pass regressions. The only measure where working memory moderated an attachment effect was in the first-pass regressions data from the noun region. Readers with higher working memory capacity were less likely to regress from the noun region than readers with lower working memory capacity, relative to the unambiguous baseline condition, when the relative clause attached to the first noun. Finally, there was a fixation time-regressions trade off in the pre-noun region. The ambiguous conditions had greater first-pass, regression path, and total time than the unambiguous condition, but the unambiguous condition had substantially more first-pass regressions than the ambiguous conditions. These effects were likely the result of the segmentation difference between the unambiguous and ambiguous conditions, which was an integral component of the experimental manipulation. Finally, at and following the point of disambiguation (the noun region), there was no indication that the Noun 1 and either conditions were more difficult to process than the unambiguous condition, which reinforces the idea that readers overall preferred to attach the relative clause to the first noun and that having a choice of two potential hosts did not by itself create processing costs. 
Before interpreting these data, it is important to note some limitations of the current experiment. First, the absence of working memory by attachment interactions cannot be unambiguously interpreted as indicating that working memory limitation plays no role in the resolution of this attachment ambiguity. Despite a number of positive effects of working memory on baseline processing times, the absence of such effects could reflect a mundane Type II error.

Another limitation of the current study is that prosody, implicit or otherwise, was not directly manipulated. The fact that readers preferred the first noun over the second under these segmentation conditions shows that segmentation is doing something. The fact that this result is predicted by Swets and colleagues' (2007) implicit prosody account, and the fact that the on-line preference matches their off-line assessment should all count in favor of implicit prosody. Having said that, the evidence is still indirect, and so other factors may have actually caused Noun 2 to be dispreferred. Additional research will be necessary to definitively tie results like these to prosodic factors. One possibility would be to explicitly manipulate prosodic grouping in auditory stimuli and test whether this manipulation affects listeners' off-line and on-line attachment preferences.

The main positive finding from the experiment was that readers preferred to attach the relative clause to the first noun rather than the second. This pattern of results is entirely consistent with the results obtained in off-line judgment (Swets et al. 2007) and differs somewhat from previous experiments involving this sentence type. For example, in Traxler and colleagues' (1998) study, most of the numerical effects were in the opposite direction (with Noun 2 attachment being numerically but not statistically faster than Noun 1 attachment). In the Traxler (2007) study, there was some indication that readers overall preferred the first noun, but those effects were limited to the pre-noun region. Further, that latter study produced an interaction of working memory capacity and attachment preferences, such that processing times for noun-2 attached relative clauses increased with increases in working memory capacity. No such working memory effects were in evidence in the current experiment. The preference for the first noun over the second, and the absence of working memory moderation of this preference are both consistent with Swets and colleagues' off-line results.

The larger question that this experiment was designed to address is how working memory capacity influences sentence processing. The shared resource view (Just and Carpenter 1992; Just et al. 1996) proposes that working memory resources are shared across cognitive tasks and across processing and storage within tasks. Hence, as storage demands increase, less working memory capacity will be available to carry out processes. For the kinds of sentences tested here, the shared resource view predicts an interaction of working memory capacity and attachment site. Specifically, low capacity comprehenders would be expected to have greater difficulty maintaining a trace of the distant attachment site (the first noun), and so they should have an easier time processing sentences where the relative clause attaches to the second noun. There was some indication that this was the case. The negative relationship between working memory capacity and first-pass regressions in the noun region when the relative clause attached to the first noun is consistent with this aspect of the shared resource account. This effect also resembles the regression-path and total-time effect obtained in the post-noun region of a previous study Traxler (2007). However, the fact that the effect occurred only in first-pass regressions and was not found in any of the other measures or any other scoring region is ample grounds for a cautious approach. Further, it is worth noting that although dual task paradigms often produce working memory by text characteristic interactions, single-task paradigms involving syntactic manipulations often do not (for an overview, see Traxler et al. 2005; Traxler 2007). 
The fairly early emergence of the Noun 1 preference (in regression path time at the noun) coupled with a general absence of working memory effects is consistent with Swets and colleagues' (2007) and Felser and colleagues (2003) claims about implicit prosody in the resolution of adjunct attachment ambiguity. On these accounts, encouraging readers to group the two nouns in the initial complex NP into a single prosodic unit simultaneously increases the salience of the first noun and decreases the salience of the second.

One important remaining issue is: What does the line break do that renders the first noun more attractive as an attachment site for the relative-clause modifier? Why does the line break make the first noun more "salient" than the second? There are a number of possible influences. First, having a line break in between the noun-phrase complex and the relativeclause modifier gives readers more time to interpret the noun-phrase before they encounter the modifier. Under those conditions, the details of the syntactic structure within the noun phrase will have more time to decay and readers will have more time to develop a unified semantic interpretation of the entire noun phrase. Most processing accounts assume that as comprehenders recover the meaning of the utterance, the syntactic details either decay or are suppressed. Either way, they become less accessible. Once the noun-phrase complex has been interpreted to some degree, the first noun will serve as the head of a unified representation, and so would be relatively more available as an attachment site for the relative clause modifier. Alternatively, it may be that speakers insert longer prosodic breaks between the noun-phrase complex and the modifier in those cases where they intend to modify the first noun, and shorter breaks when they intend to modify the second. Readers' implicit prosodic contours when there is a line break would therefore more closely match the explicit prosodic contours that they have been exposed to in cases where the first noun is modified. The reader might respond on the basis of this implicit prosody even if the representation of the nounphrase-complex is still in its "raw", fully syntactically structured state. Of course, these two hypotheses are not mutually exclusive. Additional time leading to semantic consolidation and the alignment of implicit and explicit prosody could both contribute to readers favoring the first noun.

When the first noun is made more prominent, readers, regardless of working memory capacity, should prefer to attach the relative clause to the more salient first noun, which is the pattern which occurred in the noun and post-noun regions in the current experiment. Further, these effects were not moderated by working memory capacity. Hence, one possible conclusion from the current results is that working memory differences have a limited effect on the processing of sentences like those tested here. Despite the fact that Noun 2 attachment should impose a lower working memory load than Noun 1 attachment, readers regardless of working memory capacity preferred to attach the relative clause to the first noun. This is in contrast with previous studies that showed balanced preferences. It appears therefore that attachment preferences in this instance were less affected by working memory restrictions than by some other aspect of the stimuli, the most likely candidate being implicit prosody as that is likely to be affected by the segmentation manipulation. Therefore, a sentence processing account that includes working memory limitations as an influence on processing speed will have to incorporate more complex assumptions to explain how syntactic, semantic, and prosodic factors interact to increase or decrease the processing load imposed by different kinds of sentences.

Alternatively, one might adopt a simplifying assumption that reduces the influence of working memory over attachment preferences. For example, one might conclude that the working memory tests used here and elsewhere really serve as proxies for other individual difference variables. Even the shared resource account incorporates a notion of efficiency or automaticity to explain why practiced tasks appear to impose lower working memory loads 
(Just and Varma 2002; cf. MacDonald and Christiansen 2002). Alternative interpretations of working memory test performance include the ability to switch between tasks or deploy attention strategically (see Ericsson and Kintsch 1995; Traxler et al. 2005). It is possible, for example, that higher verbal working memory test scores are a function of greater efficiency of the component language interpretation processes that the task entails, which in turn could be a reflection of greater exposure to the language or more practice. These differences in engagement with the language could easily translate into greater sensitivity to semantic aspects of different structural configurations (as suggested by Pearlmutter and MacDonald 1995). The fact that segmentation changes both off-line and on-line attachment preferences for sentences like those tested here is not easy to explain if working memory limitations are the major factor that determines attachment preferences. It may be better, then, to appeal to phrasal grouping and prosodic factors that have a well-established record of moderating syntactic effects (e.g., Frazier 1990; Kjelgaard and Speer 1999; Speer et al. 1996).

Acknowledgements The author wishes to thank Kristen Tooley for assistance in data collection. This project was supported by awards from the National Science Foundation (NSF\#0446618) and the National Institutes of Health, National Institute of Child Health and Human Development (NIH\#040865). Many thanks to an anonymous reviewer for raising this issue and offering a number of very fine suggestions.

Open Access This article is distributed under the terms of the Creative Commons Attribution Noncommercial License which permits any noncommercial use, distribution, and reproduction in any medium, provided the original author(s) and source are credited.

\section{Appendix}

These are the test sentences for the experiment. The sentences were all displayed on a single line. The "/" marks indicate where the sentences were segmented for statistical analysis. The "/" marks were not displayed during the actual experiment.

The writer of the letter//that had/ blonde hair/ arrived this/ morning. The letter of the writer//that had/ blonde hair/ arrived this/ morning. The sister of the writer//that had/ blonde hair/ arrived this/ morning. The writer/that had/ blonde hair/ arrived this/ morning.

The singer of the song//that had/ long eyelashes/ wasn't very/ smart.

The song of the singer//that had/ long eyelashes/ wasn't very/ smart.

The aunt of the singer//that had/ long eyelashes/ wasn't very/ smart.

The singer /that had/ long eyelashes/ wasn't very/ smart.

The criminal of the gang//that had/ a long scar/ disappeared last/ Monday.

The gang of the criminal//that had/ a long scar/ disappeared last/ Monday.

The brother of the criminal//that had/ a long scar/ disappeared last/ Monday.

The criminal /that had/ a long scar/ disappeared last/ Monday.

The valley of the flowers//that had/ the old castle/ excited the/ tourists.

The flowers of the valley//that had/ the old castle/ excited the/ tourists.

The village of the valley//that had/ the old castle/ excited the/ tourists.

The valley /that had/ the old castle/ excited the/ tourists.

The editor of the thesis//that had/ the big nose/ made a/ lot of sense.

The thesis of the editor//that had/ the big nose/ made a/ lot of sense.

The father of the editor//that had/ the big nose/ made a/ lot of sense.

The editor/that had/ the big nose/ made a/ lot of sense.

The house of the painter//that had/ the small windows/ looked odd./ 
The painter of the house//that had/ the small windows/ looked odd. \{ The bedroom of the house//that had/ the small windows/ looked odd. The house /that had/ the small windows/ looked odd./

The drugs of the supplier//that had/ a nasty effect/ hurt everyone. The supplier of the drugs//that had/ a nasty effect/ hurt everyone. The chemicals of the drugs // that had a nasty effect hurt everyone. The drugs /that had/ a nasty effect/ hurt everyone.

The inventor of the machine//that had/ the goatee/ was amazing. The machine of the inventor//that had/ the goatee/ was amazing. The brother of the inventor//that had/ the goatee/ was amazing. The inventor/that had/ the goatee/ was amazing.

The plains of the tribe//that had/ the rich topsoil/ looked strange The tribe of the plains//that had/ the rich topsoil/ looked strange The hills of the plains//that had/ the rich topsoil/ looked strange. The plains /that had/ the rich topsoil/ looked strange The car of the driver//that had/ the two carbeurators/ excited us. The driver of the car//that had/ the two carbeurators/ excited us. The engine of the car//that had/ the two carbeurators/ excited us. The car/that had/ the two carbeurators/ excited us.

The attorney of the company//that had/ a cleft chin/ bothered me. The company of the attorney//that had/ a cleft chin/ bothered me. The brother of the attorney//that had/ a cleft chin/ bothered me. The attorney/that had/ a cleft chin/ bothered me.

The church of the bishop//that had/ the large spires/ faced a/ lake. The bishop of the church//that had/ the large spires/ faced a/ lake. The towers of the church//that had/ the large spires/ faced a/ lake. The church /that had/ the large spires/ faced a/ lake.

The forest of the animals//that had/ the big clearings/ pleased us. The animals of the forest//that had/ the big clearings/ pleased us. The valleys of the forest//that had/ the big clearings/ pleased us. The forest /that had/ the big clearings/ pleased us.

The thesis of the editor//that had/ the misspellings/ was confusing. The editor of the thesis//that had/ the misspellings/ was confusing. The chapter of the thesis//that had/ the misspellings/ was confusing. The thesis /that had/ the misspellings/ was confusing.

The bishop of the church//that had/ the funny eyebrows/ looked odd. The church of the bishop//that had/ the funny eyebrows/ looked odd. The sister of the bishop//that had/ the funny eyebrows/ looked odd.

The bishop /that had/ the funny eyebrows/ looked odd.

The driver of the car//that had/ the moustache/ was pretty/ cool. The car of the driver//that had/ the moustache/ was pretty/ cool. The son of the driver//that had/ the moustache/ was pretty/ cool. The driver /that had/ the moustache/ was pretty/ cool.

The manager of the factory//that had/ the loud voice/ was efficient. The factory of the manager//that had/ the loud voice/ was efficient. The brother of the manager//that had/ the loud voice/ was efficient. The manager/that had/ the loud voice/ was efficient.

The gold of the miner//that had/ the impurities/ isn't worth/ much.

The miner of the gold//that had/ the impurities/ isn't worth/ much. 
The gold of the batch//that had/ the impurities/ isn't worth/ much.

The gold /that had/ the impurities/ isn't worth/ much.

The king of the mountain//that had/ the sideburns/ impressed Arthur.

The mountain of the king//that had/ the sideburns/ impressed Arthur.

The minister of the king//that had/ the sideburns/ impressed Arthur.

The king /that had/ the sideburns/ impressed Arthur.

The director of the orchestra//that had/ a big forehead/ played well.

The orchestra of the director//that had/ a big forehead/ played well.

The neighbor of the director//that had/ a big forehead/ played well.

The director/that had/ a big forehead/ played well.

The supplier of the drugs//that had/ a crooked grin/ killed a/ kid.

The drugs of the supplier//that had/ a crooked grin/ killed a/ kid.

The uncle of the supplier//that had/ a crooked grin/ killed a/ kid.

The supplier /that had/ a crooked grin/ killed a/ kid.

The chapter of the author//that had/ the preface/ is causing/ a stir.

The author of the chapter//that had/ the preface/ is causing/ a stir.

The draft of the chapter//that had/ the preface/ is causing/ a stir.

The chapter /that had/ the preface/ is causing/ a stir.

The restaurant of the chef//that had/ the blue tiles/ pleased us.

The chef of the restaurant//that had/ the blue tiles/ pleased us.

The garden of the restaurant//that had/ the blue tiles/ pleased us.

The restaurant /that had/ the blue tiles/ pleased us.

The animals of the forest//that had/ the big fangs/ frightened us.

The forest of the animals//that had/ the big fangs/ frightened us.

The mouths of the animals//that had/ the big fangs/ frightened us.

The animals /that had/ the big fangs/ frightened us.

\section{References}

Blozis, S. A., \& Traxler, M. J. (2007). Analyzing individual differences in sentence processing performance using multilevel models. Behavior Research Methods, 39, 31-38.

Brysbaert, M., \& Mitchell, D. C. (1996). Modifier attachment in sentence processing: Evidence from Dutch. The Quarterly Journal of Experimental Psychology. A, Human Experimental Psychology, 49, 664-695. doi:10.1080/027249896392540.

Caplan, D., \& Waters, G. S. (1995). Aphasic disorders of syntactic comprehension and working memory capacity. Cognitive Neuropsychology, 12, 637-649. doi:10.1080/02643299508252011.

Caplan, D., \& Waters, G. S. (1999). Verbal working memory and sentence comprehension. The Behavioral and Brain Sciences, 22, 77-126.

Carreiras, M., \& Clifton, C., Jr. (1993). Relative clause interpretation preferences in Spanish and English. Language and Speech, 36, 353-372.

Cuetos, F., \& Mitchell, D. C. (1988). Cross-linguistic differences in parsing: Restrictions on the use of the late closure strategy in Spanish. Cognition, 30, 73-105.

Daneman, M., \& Carpenter, P. A. (1980). Individual differences in comprehending and producing words in context. Journal of Verbal Learning and Verbal Behavior, 19, 450-466. doi:10.1016/S0022-5371(80)90312-6.

Ericsson, A., \& Kintsch, W. (1995). Long term working memory. Psychological Review, 102, 211-245. doi:10. 1037/0033-295X.102.2.211.

Felser, C., Marinis, T., \& Clahsen, H. (2003). Children's processing of ambiguous sentences: A study of relative clause attachment. Language Acquisition: A Journal of Developmental Linguistics, 11, 127-163. doi:10.1207/s15327817la1103_1.

Frazier, L. (1979). On comprehending sentences: Syntactic parsing strategies. Ph.D. dissertation, University of Connecticut. West Bend, IN: Indiana University Linguistics Club. 
Frazier, L. (1990). Parsing modifiers: Special purpose routines in the human sentence processing mechanism? In D. Balota, G. B. Flores d'Arcais, \& K.Rayner (Eds.), Comprehension processes in reading (pp. 303-330). Hillsdale, NJ: Erlbaum.

Frazier, L., \& Clifton, C., Jr. (1996). Construal. Cambridge, MA: MIT Press.

Gibson, E. (2000). The dependency locality theory: A distance-based theory of linguistic complexity. In A. Marantz, Y. Miyashita, \& W. O'Neil (Eds.), Image, language, brain: Papers from the first mind articulation project symposium (pp. 94-126). Cambridge, MA: MIT Press.

Gilboy, E. J., Sopena, M., Clifton, C., Jr, \& Frazier, L. (1995). Argument structure and association preferences in Spanish and English compound NPs. Cognition, 54, 131-167. doi:10.1016/0010-0277(94)00636-Y.

Just, M. A., \& Carpenter, P. A. (1992). A capacity theory of comprehension: Individual differences in working memory capacity. Psychological Review, 99, 122-149. doi:10.1037/0033-295X.99.1.122.

Just, M. A., Carpenter, P. A., \& Keller, T. A. (1996). The capacity theory of comprehension: New frontiers of evidence and arguments. Psychological Review, 103, 773-780. doi:10.1037/0033-295X.103.4.773.

Just, M. A., \& Varma, S. (2002). A hybrid architecture for working memory: Reply to MacDonald and Christiansen (2002). Psychological Review, 109, 55-65. doi:10.1037/0033-295X.109.1.55.

King, J. W., \& Just, M. A. (1991). Individual differences in syntactic parsing: The role of working memory. Journal of Memory and Language, 30, 580-602. doi:10.1016/0749-596X(91)90027-H.

King, J. W., \& Kutas, M. (1995). Who did what and when? Using word- and clause-level ERPs to monitor working memory usage in reading. Journal of Cognitive Neuroscience, 7, 376-395. doi:10.1162/jocn.1995. 7.3.376.

Kjelgaard, M. M., \& Speer, S. R. (1999). Prosodic facilitation and interference in the resolution of temporary syntactic closure ambiguity. Journal of Memory and Language, 40, 153-194. doi:10.1006/jmla.1998.2620.

MacDonald, M. C., \& Christiansen, M. C. (2002). Reassessing working memory: Comment on Just and Carpenter (1992) and Waters and Caplan (1996). Psychological Review, 109, 35-54. doi:10.1037/0033-295X. 109.1.35.

Pearlmutter, N. J., \& MacDonald, M. E. (1995). Individual differences and probabilistic constraints in syntactic ambiguity resolution. Journal of Memory and Language, 34, 521-542. doi:10.1006/jmla.1995.1024.

Raudenbush, S. W., \& Bryk, A. S. (2002). Hierarchical linear models: Applications and data analysis methods (2nd ed.). Newbury Park, CA: Sage.

Rayner, K., Warren, T., Juhasz, B. J., \& Liversedge, S. P. (2004). The effect of plausibility on eye-movements in reading. Journal of Experimental Psychology. Learning, Memory, and Cognition, 30, 1290-1301. doi:10. 1037/0278-7393.30.6.1290.

Snijders, T., \& Bosker, R. (1999). Multilevel analysis. London: Sage.

Speer, S. R., Kjelgaard, M. M., \& Dobroth, K. M. (1996). The influence of prosodic structure on the resolution of temporary syntactic closure ambiguities. Journal of Psycholinguistic Research, 25, 249-271. doi:10. 1007/BF01708573.

Swets, B., Desmet, T., Hambrick, D. Z., \& Ferreira, F. (2007). The role of working memory in syntactic ambiguity resolution: A psychometric approach. Journal of Experimental Psychology: General, 136, 64-81.

Traxler, M. J. (2007). Working memory contributions to relative clause attachment processing: A hierarchical linear modeling analysis. Memory \& Cognition, 35, 1107-1121.

Traxler, M. J., Morris, R. K., \& Seely, R. E. (2002). Processing Subject and object relative clauses: Evidence from eye-movements. Journal of Memory and Language, 47, 69-90. doi:10.1006/jmla.2001.2836.

Traxler, M. J., Pickering, M. J., \& Clifton, C., Jr. (1998). Adjunct attachment is not a form of lexical ambiguity resolution. Journal of Memory and Language, 39, 558-592. doi:10.1006/jmla.1998.2600.

Traxler, M. J., \& Tooley, K. M. (2007). Lexical mediation and context effects in parsing. Brain Research, $1146,59-74$.

Traxler, M. J., Williams, R. S., Blozis, S. A., \& Morris, R. K. (2005). Working memory, animacy, and verb class in the processing of relative clauses. Journal of Memory and Language, 53, 204-224. doi:10.1016/j. jml.2005.02.010.

Turner, M. L., \& Engle, R. W. (1989). Is working memory capacity task dependent? Journal of Memory and Language, 28, 127-154. doi:10.1016/0749-596X(89)90040-5.

Waters, G. S., \& Caplan, D. (1992). The capacity theory of sentence comprehension: Critique of Just and Carpenter. Psychological Review, 103, 761-772. doi:10.1037/0033-295X.103.4.761.

Waters, G. S., \& Caplan, D. (1996a). The measurement of verbal working memory capacity and its relation to reading comprehension. Quarterly Journal of Experimental Psychology, 49, 51-79. doi:10.1080/ 027249896392801.

Waters, G. S., \& Caplan, D. (1996b). Processing resource capacity and the comprehension of garden path sentences. Memory \& Cognition, 24, 342-355.

Waters, G. S., \& Caplan, D. (2003). The reliability and stability of verbal working memory measures. Behavior Research Methods, Instruments, \& Computers, 35, 550-564. 
Waters, G. S., Caplan, D., \& Rochon, E. (1995). Processing capacity and sentence comprehension in patients with Alzheimer's disease. Cognitive Neuropsychology, 12, 1-38. doi:10.1080/02643299508251990.

Zagar, D., Pynte, J., \& Rativeau, S. (1997). Evidence for early-closure attachment on first-pass reading times in French. The Quarterly Journal of Experimental Psychology. A, Human Experimental Psychology, 50, 421-438. doi:10.1080/027249897392161. 